\title{
Development and Assessment of a Smartphone Application for Irrigation
}

\section{Scheduling in Cotton}

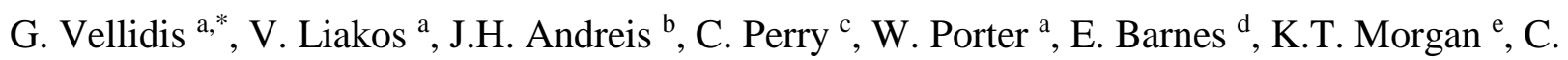

Fraisse $^{\mathrm{b}}$, K.W. Migliaccio ${ }^{\mathrm{b}}$

${ }^{\text {a }}$ University of Georgia, Crop \& Soil Sciences Department, 2360 Rainwater Rd, Tifton, GA 31793-5766, United States

${ }^{\mathrm{b}}$ University of Florida, Agricultural and Biological Engineering Department, PO Box 110570, 1741 Museum Road, Gainesville, FL 32611-0570, United States

${ }^{c}$ University of Georgia, Stripling Irrigation Research Park, 8207 GA-37, Camilla, GA 31730, United States

${ }^{\mathrm{d}}$ Cotton Incorporated, 6399 Weston Parkway, Cary, NC 27513, United States

${ }^{\text {e }}$ University of Florida, IFAS Southwest Research and Education Center, 2685 SR 29 North Immokalee, FL 34142, United States

Keywords: Crop coefficient, Soil water balance, Phenology, GDDs

\section{Abstract}

The goal of this work was to develop an easy-to-use and engaging irrigation scheduling tool for cotton which operates on a smartphone platform. The model which drives the Cotton SmartIrrigation App (Cotton App) is an interactive ET-based soil water balance model. The Cotton App uses meteorological data from weather station networks, soil parameters, crop

*Corresponding author. Tel.: +1 229386 3442, email address: yiorgos@uga.edu

\section{Abbreviations:}

$\mathrm{ET}=$ evapotranspiration, $\mathrm{ETo}=$ reference evapotranspiration, $\mathrm{ETc}=$ crop evapotranspiration, $\mathrm{FAWN}=$ Florida Automated Weather Network, FRET = forecast reference evapotranspiration, GAEMN = Georgia Automated Environmental Monitoring Network, GDDs = growing degree days, IMZs = irrigation management zones, $\mathrm{Kc}=$ crop coefficient, NOAA NWS = National Oceanic and Atmospheric Administration Weather Service, RZSWD = root zone soil water deficit, SIRP = University of Georgia's Stripling Irrigation Research Park, UGA SSA = University of Georgia Smart Sensor Array 
phenology, crop coefficients, and irrigation applications to estimate root zone soil water deficits (RZSWD) in terms of percent as well as of inches of water. The Cotton App sends notifications to the user when the RZSWD exceeds $40 \%$, when phenological changes occur, and when rain is recorded at the nearest weather station. It operates on both iOS and Android operating systems and was released during March 2014. The soil water balance model was calibrated and validated during 2012 and 2013 using data from replicated plot experiments and commercial fields. The Cotton App was evaluated in field trials for three years and performed well when compared to other irrigation scheduling tools. Its geographical footprint is currently limited to the states of Georgia and Florida, United States, because it is enabled to use meteorological data only from weather station networks in these states. A new version is currently under development which will use national gridded meteorological data sets and allow the Cotton App to be used in most cotton growing areas of the United States.

\section{Introduction}

Cotton (Gossypium hirsutum L.) is the most important fiber crop in the world and one of the most important agronomic crops in the United States where in 2014 it had a production value in excess of USD 5 billion. It is grown in 17 states across the southern half of the United States with the annual production area ranging from 5.1 to 6.3 million ha. Cotton is an intensively managed crop which requires varying amounts of water during its phenological stages to maximize yield (Vellidis et al. 2009; 2011).

In the United States, the cotton crop under irrigation has increased steadily over the past two decades because irrigation serves both to reduce risk of crop loss but also to build resiliency and yield stability. Approximately $40 \%$ of U.S. cotton is currently irrigated but irrigation water is 
becoming limited in many cotton growing areas such as the Texas high plains, Arizona, and California and competition for water is increasing rapidly in areas normally associated with plentiful water resources. As a result, the organizations representing growers are investing in the development of irrigation scheduling tools which improve irrigation water use efficiency. In response, a significant amount of research has been conducted on this topic.

Cotton's water needs are a function of phenological stage (Fig. 1). Evapotranspiration (ET) is also an important factor in estimating cotton's daily water use and several cotton irrigation scheduling tools have been developed which use estimated crop ET (ETc) to develop irrigation recommendations. These models typically use a crop coefficient $(\mathrm{Kc})$ which represents the crops phonological stage to calculate ETc from a reference ET (ETo) as shown in equation 1 (Jensen , 1968; Doorenbos and Pruitt 1975, 1977; Burman et al. 1980a, b; Allen et al. 1998)..

$$
E T_{c}=E T o \times K c
$$

Models which use only ETc to estimate irrigation requirements are simple and easy-to-use but they do not consider moisture available in the soil profile which sometimes leads to overapplication of irrigation water. Incorporating soil water balance increases accuracy but also increases the number of parameters needed as well as the complexity of the model.

The increasing availability of online environmental measurements required for ET-based irrigation schedules (i.e., temperature, solar radiation, relative humidity, wind speed, and rainfall) published by local, state, and regional weather station networks has facilitated the development of a wide variety of web-based irrigation scheduling tools. The University of Florida's PeanutFARM (Field Agronomic Resource Manager; http://agronomy.ifas.ufl.edu/peanutfarm) is a web-based irrigation scheduling tool for southeastern peanut production. PeanutFARM uses cumulative adjusted growing degree days (aGDD) (Rowland et al., 2006) and ET from weather station 
networks to estimate crop water use and provides daily irrigation recommendations. Washington State University's AgWeatherNet (http://weather.wsu.edu) uses meteorological data from nine weather station networks in the western United States and Canada to develop irrigation scheduling recommendations for 56 agronomic and horticultural crops. The University of Arkansas Irrigation Scheduler (http://irrigweb.uaex.edu) also develops irrigation scheduling for several agronomic crops including cotton. It has been available in various forms for 20 years and recently became available online. All of these web-based tools require regular, sometimes daily interaction with the user and/or can be accessed effectively only via a desktop or laptop computer which makes them cumbersome to use consistently throughout the growing season.

Recent technological advances that allow for widespread internet access through handheld devices such as tablets and smartphones provide a novel platform on which to deliver sophisticated yet easy-to-use ET-based irrigation scheduling tools. Smartphone tools, typically referred to as smartphone applications or apps, are being developed at exponential rates for every imaginable use. The functionality of an app differs from a web tool in that apps are with the user at all times since they reside on the smartphone, are readily accessible, and engage the user through notifications (Migliaccio et al., 2015; 2016). Some apps use notifications, similar to text messages, to prompt users to respond to critical events and eliminate the need to interact with the tool on a daily basis.

Agricultural researchers and extension specialists are entering the fray and offering apps for a variety of uses ranging from pest identification to irrigation scheduling. Migliaccio et al. (2016) presented a suite of SmartIrrigation apps which were recently released to provide real-time irrigation schedules for avocado, citrus, cotton, peanut, strawberry, turf, and vegetables. Information about and links to download these apps can be found at www.smartirrigationapps.org. 
This paper describes the Cotton SmartIrrigation App (hereafter referred to as the Cotton App) which was released in 2014. Our objectives were to develop a novel ET-based irrigation scheduling tool for cotton that requires minimal user interaction, is delivered to the user on a smartphone platform, and outperforms many other irrigation scheduling tools.

\section{Materials and Methods}

The model which drives the Cotton App is an interactive ET-based soil water balance model. It uses meteorological data, soil parameters, crop phenology, crop coefficients, and irrigation applications to estimate root zone soil water deficits (RZSWD) in terms of percent and inches of water and provides these two pieces of information to the user. The model does not deliver irrigation application recommendations. However, the user may utilize the RZSWD information to make appropriate irrigation decisions.

\subsection{ET and $K c$}

The model uses meteorological data to calculate ETo using the Penman-Monteith equation (Allen et al. 1998). This method, also known as FAO 56, is widely accepted for irrigation scheduling. The model then uses Kc to estimate ETc as shown in equation 1. For annual crops, Kc changes with phenological stage. Kc typically begins with small values after emergence and increases to 1.0 or above when the crop has the greatest water demand. Kc decreases as crops reach maturity and begin to senesce. Fig. 1 presents measured water use and crop coefficient functions for cotton in Mississippi and Louisiana (Perry and Barnes, 2012). We used information from these and other studies to develop a prototype Kc curve for southern Georgia and northern Florida conditions. The curve was calibrated and validated with a series of plot and field studies 
in 2012 and 2013. Details of the calibration and validation effort are provided below. In the model, changes in phenology and associated changes in Kc are driven by accumulated heat units commonly referred to as growing degree days (GDDs). GDDs are calculated using equation 2.

$$
G D D=\frac{T_{\max }+T_{\min }}{2}-T_{\text {base }}
$$

For cotton, $\mathrm{T}_{\text {base }}$ is $60^{\circ} \mathrm{F}$. Any temperature below $T_{\text {base }}$ is set to $T_{\text {base }}$ before calculating the average. Fig. 2 presents the relationship between GDDs and Kc, and the corresponding phenological stages as used in the model. GDDs required for phenological stages are derived from Ritchie et al. (2004).

\subsection{Soil Water Balance Model}

ETc is used by the model to estimate daily crop water use. ETc, measured precipitation, and irrigation are then used to estimate the plant available soil water. Plant available soil water is a function of the soil's plant available water holding capacity and current rooting depth. The model allows users to select from one of seven generic soils shown in Table 1. As the plant rooting system grows, the depth of the profile from which the plant can extract water also increases. In the model, the initial rooting zone depth is $0.15 \mathrm{~m}(6 \mathrm{in})$ and increases by $7.5 \mathrm{~mm} \mathrm{day}^{-1}\left(0.3 \mathrm{in} \mathrm{day}^{-}\right.$ $\left.{ }^{1}\right)$ until it reaches a maximum depth of $0.75 \mathrm{~m}$ (30 in). At emergence, the soil profile from 0 to $0.75 \mathrm{~m}$ is assumed to be at $85 \%$ of maximum plant available soil water holding capacity.

Today's plant available soil water is calculated by subtracting yesterday's ETc from yesterday's plant available soil water and adding any precipitation or irrigation measured. The model allows for three types of irrigation - high pressure overhead sprinkler, low-pressure overhead sprinkler, and subsurface drip. It uses an efficiency factor of $75 \%$ for high pressure 
sprinkler and $85 \%$ for low pressure sprinkler to account for evaporation and drift before the water droplets reach the soil and a $90 \%$ efficiency factor for subsurface drip irrigation. The model also assumes that $90 \%$ of measured precipitation reaches the soil to account for canopy interception and other losses. A maximum of $25 \mathrm{~mm}$ (1 in) and a minimum of $5 \mathrm{~mm}(0.2$ in) in daily precipitation is used in soil water balance calculations. The maximum is used because even if the RZSWD is greater than $25 \mathrm{~mm}$, it is unlikely that more than that amount will infiltrate into the soil profile during a $24 \mathrm{hr}$ period. The minimum is used because less than $5 \mathrm{~mm}$ of precipitation in a $24 \mathrm{hr}$ period does not have an appreciable effect on soil moisture. All these parameters are used to calculate root zone soil water deficit (RZSWD) in inches and \% RZSWD.

\subsection{Model Calibration and Validation}

During 2012 and 2013 we used four large plots at the University of Georgia's Stripling Irrigation Research Park (SIRP) located near Camilla in southwestern Georgia to calibrate the model and in 2013 we used five producer fields located in southwestern Georgia to validate the model. Both the plots and fields were instrumented with the University of Georgia Smart Sensor Array (UGA SSA). The UGA SSA is a fully wireless soil moisture sensing system which measures soil water tension at $0.2,0.4$, and $0.6 \mathrm{~m}\left(8,16\right.$, and 24 in) below the soil surface using Watermark ${ }^{\circledR}$ (Irrometer, Riverside, California, United States) soil moisture sensors (Vellidis et al., 2013; Liakos et al., 2015). We used the soil water tension data from the plots in 2012 and 2013 to retroactively adjust the model's Kc curve so that 50\% RZSWD coincided with a weighted root zone average soil water tension of between $40 \mathrm{kPa}$ and $50 \mathrm{kPa}$. Our experience with irrigation scheduling indicates that this range is a good irrigation threshold for cotton (Vellidis et al., 2016). Weighted average soil water tension was calculated using the following weighting equation: 
In 2013, we used the model adjustments made following the 2012 growing season to

\subsection{Meteorological Data}

Meteorological data, and especially accurate precipitation data, are critical to the Cotton App. In its current version, the Cotton App pulls meteorological data from the Georgia Automated Environmental Monitoring Network (GAEMN) (http://weather.uga.edu) and the Florida Automated Weather Network (FAWN) (http://fawn.ifas.ufl.edu) thus currently limiting the Cotton App's footprint to these two states. GAEMN maintains 83 automated meteorological stations and pushes daily data to a file transfer protocol (FTP) site from which they are accessed each morning. 
FAWN maintains 35 stations and uses a public application programming interface (API) to share daily weather data.

\subsection{Smartphone App Development}

Our design principles for the Cotton App were that it should provide the most accurate, site-specific, real-time information we could offer the user. In addition, the Cotton App would require minimum user input which, when necessary, it would solicit from the user by sending notifications. It would not be necessary for the user to check the Cotton App regularly. Finally the Cotton App would provide ready-to-use output and be engaging.

The Cotton App was designed to operate on both the iOS and Android platforms. It was developed using the official tools and programming language provided by Apple ${ }^{\circ}$ (Objective C and iOS SDK) and Google ${ }^{\circledR}$ (Java and Android SDK). The Cotton App communicates with servers and databases via specific web utilities which return data in JSON (JavaScript Object Notation) format. Code scripts are scheduled in the Crontab program of a UNIX based server to retrieve, process and store weather data from FAWN and GAEMN to run the soil water balance model. Notifications are sent to users via Apple Push Notification Service (APNS) and Google Cloud Messaging (GCM) protocols. Fig. 3 presents the flow of information between the Cotton App, server, and automated weather station networks.

\subsection{User Interaction}

After initial setup, the user is directed to the field setup screen. A user may register multiple fields but only one at a time. Field registration begins with the field location. By default, the Cotton App pins the field on a map at the smartphone's location but the user may reposition the 
pin by dragging it to the desired location (Fig. 4). Accurately locating the field's position is important because it is used to locate the weather stations nearest to the field. The user then enters a unique field name and planting date. The Cotton App automatically selects the closest weather station but also displays the next four closest weather stations and the user has the option to select any of those. Finally, the user selects soil type from the options presented in Table 1, irrigation system type, and the default irrigation rate. The default irrigation rate is the amount of irrigation the user typically applies during an irrigation event.

The main user interface screen (Fig. 5) is field-specific but the user can move between fields by swiping the screen from left to right or right to left. The circles at the top of the screen indicate the number of fields registered by the user (in Fig. 5 there are six). The circles are added in the sequence in which fields are registered and the solid circle indicate the field currently being displayed. The Edit Field button allows the user to edit any of the information entered during field setup. Below that, the Cotton App displays the current RZSWD. The bar graph on the left is scaled from 0 to $100 \%$ RZSWD and moves downwards as soil water is depleted. To the right of the bar, the RZSWD is displayed numerically and below that, in parentheses, is the amount of irrigation water required to refill the profile. When irrigation is applied, the user must record that irrigation by pressing the Add irrigation button. The Cotton App then credits the default irrigation amount (multiplied by the efficiency factor) to the soil water balance model. A sprinkler symbol indicates that an irrigation event has been added and the irrigation's effect on RZSWD is shown with a lighter shade of blue on the bar graph (Fig. 5).

Below the bar graph, the screen displays the amount of effective irrigation and effective rain added to the model on this day. If more or less than the default irrigation is added to the field or if the rain amount recorded at the nearest weather station is different from the rain received at 
the field, the user can adjust the amounts by touching the See details button (Fig. 5). Irrigation and rain amounts can be corrected retroactively for the past nine days. The Cotton App will perform best when precipitation data are accurate and the best way to provide these data is to use a local rain gage to adjust rain data recorded at the weather station.

The soil water balance model is run once a day early in the morning after the weather data for the past day are uploaded to the server. The display is updated the first time the user opens the Cotton App after the model run. The model also runs and the display updates if the user adds or removes an irrigation event, corrects rainfall amounts, or changes any of the field parameters (such as soil type) which may affect RZSWD. The Cotton App allows the user to view RZSWD, irrigation, and rain data, and growth stage data for the current day and the past nine days. Past data can be viewed by swiping along the series of ten circles located below the RZSWD display. The current day is represented by the circle at the far right.

Estimated phenological development (growth stage) and accumulated GDDs are presented at the bottom of the screen. It is important that the user ground-truth the model's changes in phenological stage as they occur because as described earlier, this is the parameter that forces changes in Kc. If the crop is not progressing at the same rate as predicted by the Cotton App, then the Kc used may be too high or too low and the RZSWD will not reflect field conditions accurately. If the discrepancies are large, use of the Cotton App should be discontinued in this field. At this time, there is no provision for the user to adjust phenological stage. Fig. 6 presents a schematic of how the Cotton App interacts with inputs and outputs.

\subsection{Notifications}

Notifications are pushed to the user when a rain event is recorded at a weather station 
associated with a registered field, when phenological changes occur, and when RZSWD exceeds $40 \%$ (Fig. 7). A $50 \%$ RZSWD or depletion of $50 \%$ of plant available soil water is a commonly accepted irrigation threshold for many agronomic crops. The Cotton App begins to push daily notifications to the user when RZSWD exceeds $40 \%$ to allow the user time to trigger the required irrigation event.

\subsection{Cotton App Performance}

For three growing seasons, 2013 - 2015, the Cotton App was a treatment in a cotton irrigation scheduling study conducted at SIRP. Every year, the Cotton App was compared to other scheduling methods some of which changed from year to year. Throughout the three years, only two other treatments were used repeatedly - the University of Georgia Extension Checkbook Method hereafter referred to as the Checkbook Method which was used in 2013, 2014 and 2015 and the UGA SSA with a $50 \mathrm{kPa}$ irrigation threshold which was used in 2014 and 2015 . Only the results from these three treatments will be discussed. Treatment yields were analyzed using an analysis of variance GLM procedure follow by means separation LSD test.

The Checkbook Method tabulates the amount of water a crop needs during each week of its life-cycle. Producers subtract the amount of precipitation received from the weekly requirements and add the remainder via irrigation. The Checkbook Method does not account for environmental conditions and so tends to over-irrigate when ET rates are low.

\section{Results and Discussion.}

\subsection{Calibration and Validation}

Fig. 8 presents the calibration results from the conservation and conventional tillage plots 
at SIRP for 2012 (top) and 2013 (bottom). In 2012 the plots were irrigated with the model using the Kc curve derived from the literature. After the growing season the Kc curve was calibrated by adjusting the Kc so that $50 \%$ RZSWD occurred when the mean weighted soil water tension from the UGA SSA sensors was approximately between 40 and $50 \mathrm{kPa}$. In 2013 the plots were irrigated utilizing the calibrated Kc curve. The Kc curve was recalibrated following the 2013 growing season and adjustments made again after the 2015 growing season. The current Kc curve is presented in Fig. 2.

Fig. 9 presents the 2013 validation results from a UGA SSA locations in four of the five commercial cotton fields. Validation was done with the model using the 2013 calibrated Kc curve. To quantify the frequency at which the Cotton App RZSWD matched measured soil water tension, Pearson correlation analysis was performed between these two variables using SPSS v.16 software (SPSS Inc, United States). The Pearson correlation coefficient (r) ranged from 0.7 to 0.8 (Table 2). In addition, we compared how many days during the growing season RZSWD exceeded 50\% and weighted soil water tension exceeded 40 and $50 \mathrm{kPa}$ as an indicator of how well the model matched the data (Table 2). In general, the match was good. In Fields 3 and 4, the spike in soil water tension at the end of the growing season (Fig. 9) is consistent with a RZSWD of around 70\% as the soil in both fields were loamy sands with relatively low water holding capacities.

\subsection{Cotton App Performance}

Table 3 summarizes the performance of the Cotton App compared to the Checkbook Method for 2013-2015 and compared to the UGA SSA with a $50 \mathrm{kPa}$ irrigation threshold for 20142015. 2013 and 2015 were wetter than normal years while 2014 was a drier than normal year. The Cotton App outperformed the Checkbook Method in terms of mean yield regardless of tillage 
treatment and did this most effectively during the two wet years. However the differences were statistically significantly different only in 2013 and 2014 because of large intra-treatment variability in yield during 2015 (Vellidis et al., 2016). The Cotton App also outperformed the Checkbook Method in irrigation water applied and water use efficiency. This is because the Checkbook Method does not take into account periods with low ET which occur frequently in wet years. The Cotton App outperformed the UGA SSA method in 2014 but in 2015, the UGA SSA conservation tillage treatment outperformed the Cotton App conservation tillage plots. The yield differences between these two irrigation treatments were statistically significant in 2014 (Table 3). By comparing the soil water tension data from all the treatments and replicated plots, it is clear that in 2015 , the treatments that maintained a drier soil profile produced the highest yields (Vellidis et al., 2016). The UGA SSA conservation tillage treatment did have a drier soil profile than the Cotton App. We hypothesize that because the Cotton App does not currently discriminate between conventional and conservation tillage, in 2015 the conservation tillage plots were over-irrigated by the Cotton App.

\subsection{Expanding the Cotton App's Geographical Footprint}

The Cotton App's geographical footprint is currently limited to Georgia and Florida for two reasons. The first is that the project team which developed the suite of SmartIrrigation Apps had already developed the protocols to use data from GAEMN and FAWN. Adding weather networks from other states which provide the meteorological data needed to calculate ETo using the Penman-Monteith equation requires additional resources but is relatively straightforward. Discussions are ongoing with two state weather networks.

The second reason inhibiting use of the Cotton App in other states is that the Kc curve 
currently used in the model was calibrated to environmental conditions found in southern Georgia and northern Florida using varieties developed for this environment. Consequently the Kc curve may not be appropriate for the environmental conditions and varieties in other regions. To make the Cotton App useable across the U.S. cotton belt will require a library of Kc curves as well as widespread access to meteorological data.

One solution to the meteorological data problem may be to use national gridded meteorological datasets offered by the U.S. National Oceanic and Atmospheric Administration Weather Service (NOAA NWS). We evaluated the NOAA NWS $4 \mathrm{~km}$ grid quantitative precipitation estimation (http://1.usa.gov/1WgkdN8) and found that it underestimates precipitation during the summer. Summer precipitation in the southeastern United States is driven by localized convective thunderstorms. As a result, in-field precipitation amounts can be substantially different from those estimated for a 4-km grid as well as from precipitation recorded at the nearest meteorological station on any given day.

NOAA NWS also recently released an experimental forecast reference ET (FRET) tool http://1.usa.gov/1Poz2va which we evaluated during the 2015 growing season for 20 locations in Florida, Georgia, and South Carolina. FRET appears to overestimate daily ET when unusually low ET is calculated from weather station data (Fig. 10). Overestimating ET during low ET days erodes the advantage that the Cotton App has over irrigation scheduling tools like the Checkbook Method. A trial version of the Cotton App using the NOAA NWS 4km grid quantitative precipitation estimation and FRET is currently under development and will be compared to the released version of the Cotton App in several locations in southern Georgia and northern Florida during the 2016 growing season. 


\subsection{Scheduling Variable Rate Irrigation with the Cotton App}

Soils within fields in many parts of the world including the southeastern United States 
system's VRI controller daily if necessary. The architecture of the Cotton App allows users to view the RZSWD for individual fields/IMZs with the swipe of a finger across the touchscreen of the smartphone.

\subsection{Final Observations}

Meteorological station-driven precipitation is the Cotton App's weakest feature since infield precipitation amounts can be significantly different from those recorded at the nearest weather station on any given day. For the Cotton App to be used most effectively and to produce the most accurate results, users should correct precipitation recorded at weather stations with data from the field. Because notifications are pushed to the user whenever precipitation is recorded at the weather station, this may be simple to do. A bigger problem may lie with rain received at the field but not recorded at the weather station, because in this case, users will not have knowledge of the event until they visit the field.

Since its release in 2014, the Cotton App has been used by 233 by growers, consultants, and researchers to schedule irrigation in 520 unique fields during the 2014 and 2015 growing seasons. Twenty updates have been released over this time period - 12 for the Android and eight for iOS platforms, respectively. Reviews from users are positive and the University of Georgia Extension Cooperative Extension Service is now actively promoting the use of the Cotton App in Georgia. An online tutorial is available at http://smartirrigationapps.org/cotton-app-development.

\section{Acknowledgements}

This work was made possible by funding from the USDA NIFA National Integrated Water Quality Program (awards \# 2011-51130-31143 and \# 2013-51130-21486), the USDA NRCS Conservation 
Innovation Grants Program (award \# 69-3A75-13-83) and grants from the Georgia Cotton Commission and Cotton Incorporated.

\section{References}

Allen, R.G., Pereira, L.S., Raes, D., Smith, M. 1998. Crop Evapotranspiration-Guidelines for Computing Crop Water Requirements. FAO Irrigation and drainage paper 56. Rome, Italy: Food and Agriculture Organization of the United Nations. ISBN 92-5-104219-5.

Burman, R.D., Wright, J.L., Nixon, P.R., Hill, R.W., 1980a. Irrigation management—water requirements and water balance. In: Irrigation, Challenges of the 80's, Proc. of the Second National Irrigation Symposium, Am. Soc. Agric. Engr, St. Joseph, MI, pp. 141-153.

Burman, R.D., Nixon, P.R., Wright, J.L., Pruitt, W.O., 1980b. Water requirements. In: Jensen, M.E. (Ed.), Design of Farm Irrigation Systems, ASAE Mono., Am. Soc. Agric. Eng., St. Joseph, MI, pp. 189-232.

Doorenbos, J., Pruitt, W.O., 1975. Guidelines for predicting crop water requirements. Irrigation and Drainage Paper No. 24, Food and Agricultural Organization, United Nations, Rome, Italy, pp. 168.

Doorenbos, J., Pruitt, W.O., 1977. Guidelines for predicting crop water requirements. Irrigation and Drainage Paper No. 24, 2nd ed., Food and Agricultural Organization, United Nations, Rome, Italy, pp. 144.

Jensen, M.E., 1968. Water consumption by agricultural plants. In: Kozlowski, T.T. (Ed.), Water Deficits and Plant Growth, Vol. II. Academic Press, Inc., New York, NY, pp. 1-22.

Liakos, V., Vellidis, G., Tucker, M., Lowrance, C., Liang, X. 2015. A decision support tool for managing precision irrigation with center pivots. In: J.V. Stafford (Ed.), Precision Agriculture 2015 - Proceedings of the 10th European Conference on Precision Agriculture 
8_84.

Perry, C.D. and E.M. Barnes. 2012. Cotton Irrigation Management for Humid Regions. Cotton Incorporated, Cary, NC. Available at http://www.cottoninc.com/fiber/AgriculturalDisciplines/Engineering/IrrigationManagement/

Ritchie, G.L., C.W. Bednarz, P.H. Jost, and S.M. Brown. 2004. Cotton growth and development. Bulletin 1252, Cooperative Extension Service, University of Georgia, Athens, Georgia, http://www.caes.uga.edu/publications.

Rowland, D. L., Sorensen, R. B., Butts, C. L., \& Faircloth, W. H. (2006). Determination of maturity and degree day indices and their success in predicting peanut maturity. Peanut Sci., 33(2), 125-136.

http://dx.doi.org/10.3146/0095-679(2006)33[125:DOMADD]2.0.CO;2.

Vellidis, G., B. Ortiz, G. Ritchie, A. Peristeropoulos, C. Perry and K. Rucker. 2009. Using GreenSeeker® to drive variable rate application of plant growth regulators and defoliants on cotton. In: van Henten, E.J., D. Goense, and C. Lokhorst (Eds.), Precision Agriculture 
'09 - Proceedings of the 7th European Conference on Precision Agriculture (7ECPA), Wageningen, the Netherlands, pp. 55-72.

Vellidis, G., H. Savelle, R. G. Ritchie, G. Harris, R. Hill, and H. Henry. 2011. NDVI response of cotton to nitrogen application rates in Georgia, USA. In: J.V. Stafford (Ed.), Precision Agriculture 2011 - Proceedings of the 8th European Conference on Precision Agriculture (8ECPA), Prague, Czech Republic, pp. 358-368.

Vellidis, G., Tucker, M., Perry, C., Reckford, D, Butts, C., Henry, H., Liakos, V., Hill, R.W., and Edwards, W. 2013. A soil moisture sensor-based variable rate irrigation scheduling system. In: J.V. Stafford (Ed.), Precision Agriculture 2013 - Proceedings of the 9th European Conference on Precision Agriculture (9ECPA), Lleida, Spain, pp.713-720. doi: 10.3920/978-90-8686-778-3.

Vellidis, G., Liakos, V., C. Perry, W. Porter, and M. Tucker. 2016. Irrigation scheduling for cotton using soil moisture sensors, smartphone apps, and traditional methods. In S. Boyd, M. Huffman and B. Robertson (eds) Proceedings of the 2016 Beltwide Cotton Conference, New Orleans, LA, National Cotton Council, Memphis, TN (paper 16779, p.772-780). 
Table 1. Plant available water capacity (AWC), field capacity (FC), and wilting point (WP) of the seven generic soil types used in the Cotton App.

\begin{tabular}{lccc}
\hline Soil type & $\begin{array}{c}\text { AWC } \\
\left(\mathrm{cm}^{3} \mathrm{~cm}^{-3}\right)\end{array}$ & $\begin{array}{c}\text { FC } \\
\left(\mathrm{cm}^{3} \mathrm{~cm}^{-3}\right)\end{array}$ & $\begin{array}{c}\text { WP } \\
\left(\mathrm{cm}^{3} \mathrm{~cm}^{-3}\right)\end{array}$ \\
\hline Sand & 0.05 & 0.10 & 0.05 \\
Loamy sand & 0.06 & 0.12 & 0.06 \\
Sandy loam & 0.10 & 0.18 & 0.08 \\
Loam & 0.14 & 0.28 & 0.14 \\
Silt loam & 0.20 & 0.31 & 0.11 \\
Clay loam & 0.14 & 0.36 & 0.22 \\
Clay & 0.12 & 0.42 & 0.30 \\
\hline
\end{tabular}

Table 2. Metrics used to quantify the frequency at which the Cotton App RZSWD matched measured soil water tension in five grower fields in southwestern Georgia during 2013.

\begin{tabular}{lcccc}
\hline \multirow{2}{*}{ Field } & $\begin{array}{c}\text { Pearson } \\
\text { Correlation } \\
\text { Coefficient }\end{array}$ & \multicolumn{3}{c}{ Occurrences Exceeding Given Thresholds } \\
\cline { 3 - 5 } & RZSWD >50\% & $\begin{array}{c}\text { Soil Water } \\
\text { Tension >40kPa }\end{array}$ & $\begin{array}{c}\text { Soil Water } \\
\text { Tension >50kPa }\end{array}$ \\
\hline Field 1 & 0.708 & 2 & 10 & 6 \\
Field 2 & 0.822 & 7 & 10 & 5 \\
Field 3 & 0.871 & 11 & 27 & 12 \\
Field 4 & 0.798 & 11 & 27 & 12 \\
Field 5 & 0.778 & 0 & 5 & 0 \\
\hline
\end{tabular}

${ }^{1}$ Significant at 0.01 . 
Table 3. Performance of the Cotton App compared to other irrigation scheduling treatments conducted at the University of Georgia's Stripling Irrigation Research Park. Cotton yield is reported as lint (fiber) yield. Treatment yields were analyzed using an analysis of variance GLM procedure follow by means separation LSD test. Means with the same t Grouping letter are not significantly different.

\begin{tabular}{|c|c|c|c|c|c|c|c|}
\hline \multirow{2}{*}{$\begin{array}{l}\text { Year } \\
\text { Rain } \\
(\mathrm{mm})^{1}\end{array}$} & \multirow[b]{2}{*}{ Scheduling Method } & \multicolumn{3}{|c|}{ Conventional Tillage } & \multicolumn{3}{|c|}{ Conservation Tillage } \\
\hline & & $\begin{array}{l}\text { Lint Yield } \\
\left(\mathrm{kg} \mathrm{ha}^{-1}\right)\end{array}$ & $\begin{array}{l}\text { Irrigation } \\
\text { (mm) }\end{array}$ & $\begin{array}{c}\text { WUE }^{2} \\
\left(\mathrm{~kg} \mathrm{ha}^{-1} \mathrm{~mm}^{-1}\right)\end{array}$ & $\begin{array}{l}\text { Lint Yield } \\
\left(\mathrm{kg} \mathrm{ha}^{-1}\right)\end{array}$ & $\begin{array}{l}\text { Irrigation } \\
(\mathrm{mm})\end{array}$ & $\begin{array}{c}\text { WUE } \\
\left(\mathrm{kg} \mathrm{ha}^{-1} \mathrm{~mm}^{-1}\right)\end{array}$ \\
\hline 2013 & Checkbook & $1289^{b}$ & 310 & 4.1 & $1513^{b}$ & 323 & 4.6 \\
\hline$(696)$ & Cotton App & $1411^{\mathrm{a}}$ & 76 & 18.5 & $1664^{\mathrm{a}}$ & 76 & 21.8 \\
\hline 2014 & Checkbook & $1915^{b}$ & 388 & 4.9 & $1860^{b}$ & 388 & 4.7 \\
\hline \multirow[t]{2}{*}{$(285)$} & Cotton App & $2067^{\mathrm{a}}$ & 231 & 8.9 & $2011^{\mathrm{a}}$ & 231 & 8.7 \\
\hline & UGA SSA $50 \mathrm{kPa}$ Threshold & $1974^{b}$ & 315 & 6.2 & $1721^{\mathrm{c}}$ & 372 & 4.6 \\
\hline 2015 & Checkbook & $1814^{\mathrm{a}}$ & 165 & 11 & $1748^{a}$ & 165 & 10.6 \\
\hline \multirow[t]{2}{*}{$(575)$} & Cotton App & $1926^{\mathrm{a}}$ & 146 & 13.1 & $1841^{\mathrm{a}}$ & 127 & 14.5 \\
\hline & UGA SSA $50 \mathrm{kPa}$ Threshold & $1849^{\mathrm{a}}$ & 108 & 17.1 & $1953^{\mathrm{a}}$ & 108 & 18.0 \\
\hline
\end{tabular}

${ }^{1}$ Precipitation in mm during the growing season.

2 WUE $=$ water use efficiency 

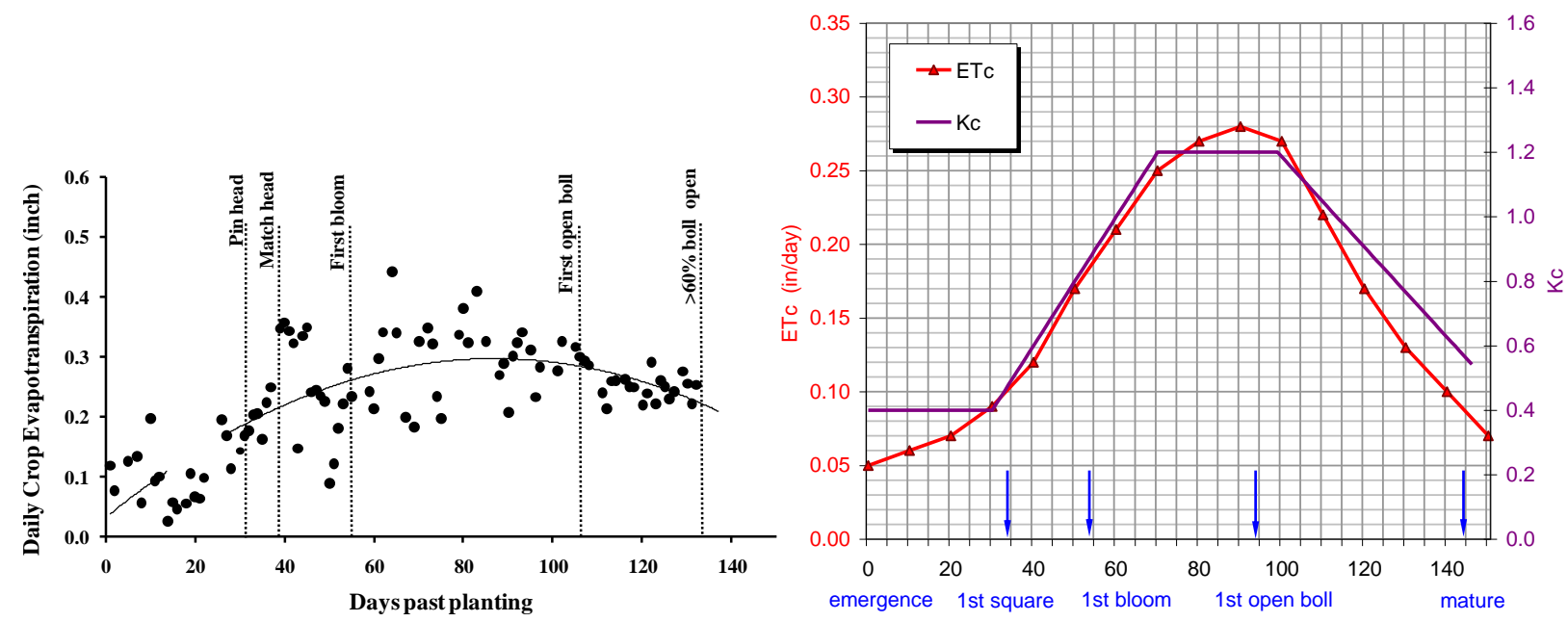

Fig. 1. Measured crop water use (ETc) from a cotton field in Louisiana over the growing season (left) and water use and crop coefficient curve for cotton in Stoneville, Mississippi (right) (Perry and Barnes, 2012).

Days After Planting (DAP) 2013

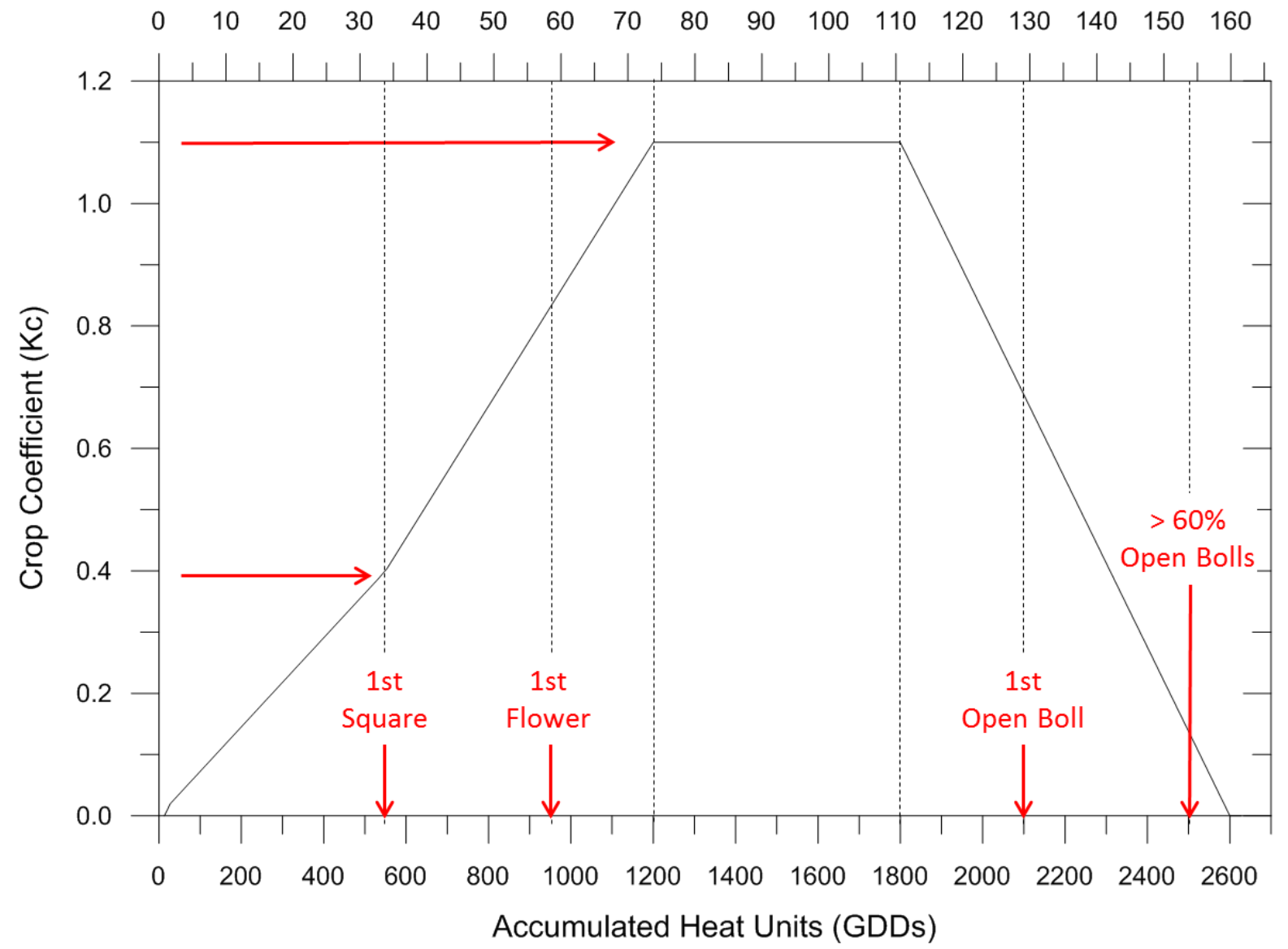

Fig. 2. Kc curve used in the model. Maximum $\mathrm{Kc}$ is 1.1 which is maintained between 1200 and 1800 GDDs. An inflection point and Kc rate change occurs at 550 GDDs. The top axis indicates how DAP coincided with GDDs in 2013. 


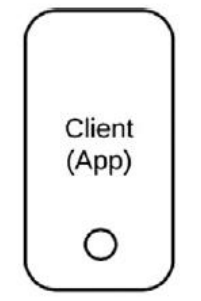

(8) Client displays information
(6) App requests and users inputs

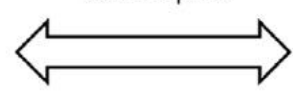

(7) Script processes and return data in JSON format

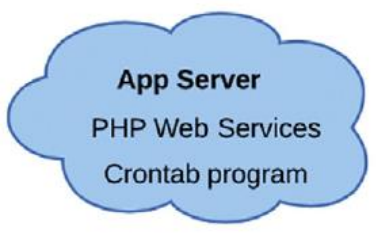

(4) Queries and data persitence to MySQL

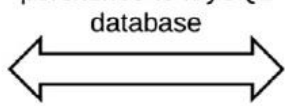

(5) Query results
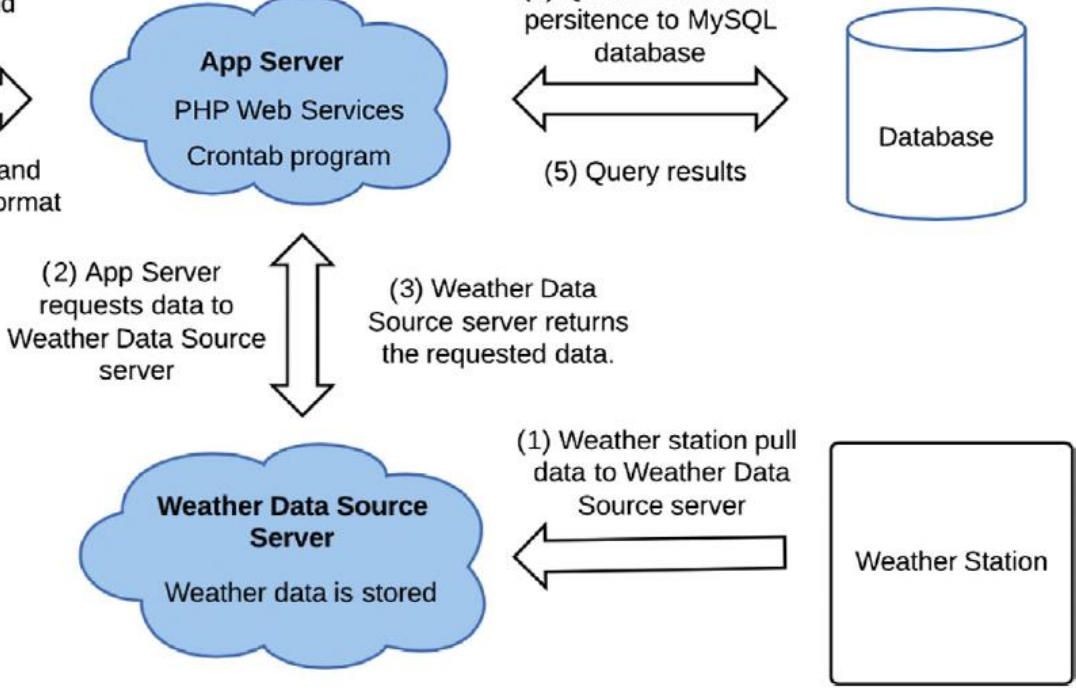

Fig. 3. Diagram of interaction among client, server and automated weather stations (Migliaccio et al., 2015).

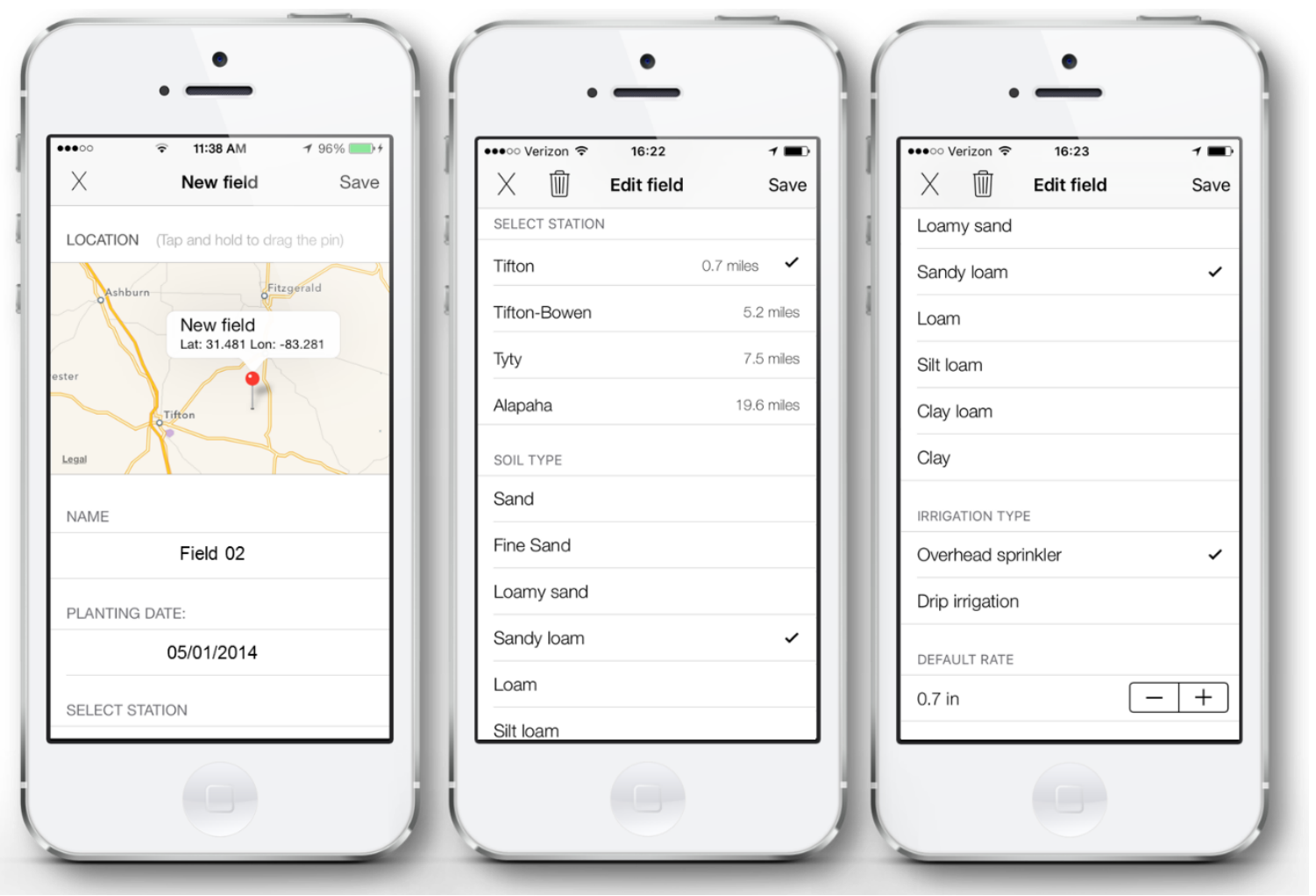

Fig. 4. Screenshots of an iPhone running the Cotton App with the new field setup screens. The Cotton App pins the field on a map at the smartphone's location but the user may reposition the field by dragging the pin (left). The Cotton App automatically selects the closest weather station (center) but also displays the next four closest weather stations and the user has the option to select any of those. The user then selects soil type (center), and irrigation system type and default irrigation rate (right). 


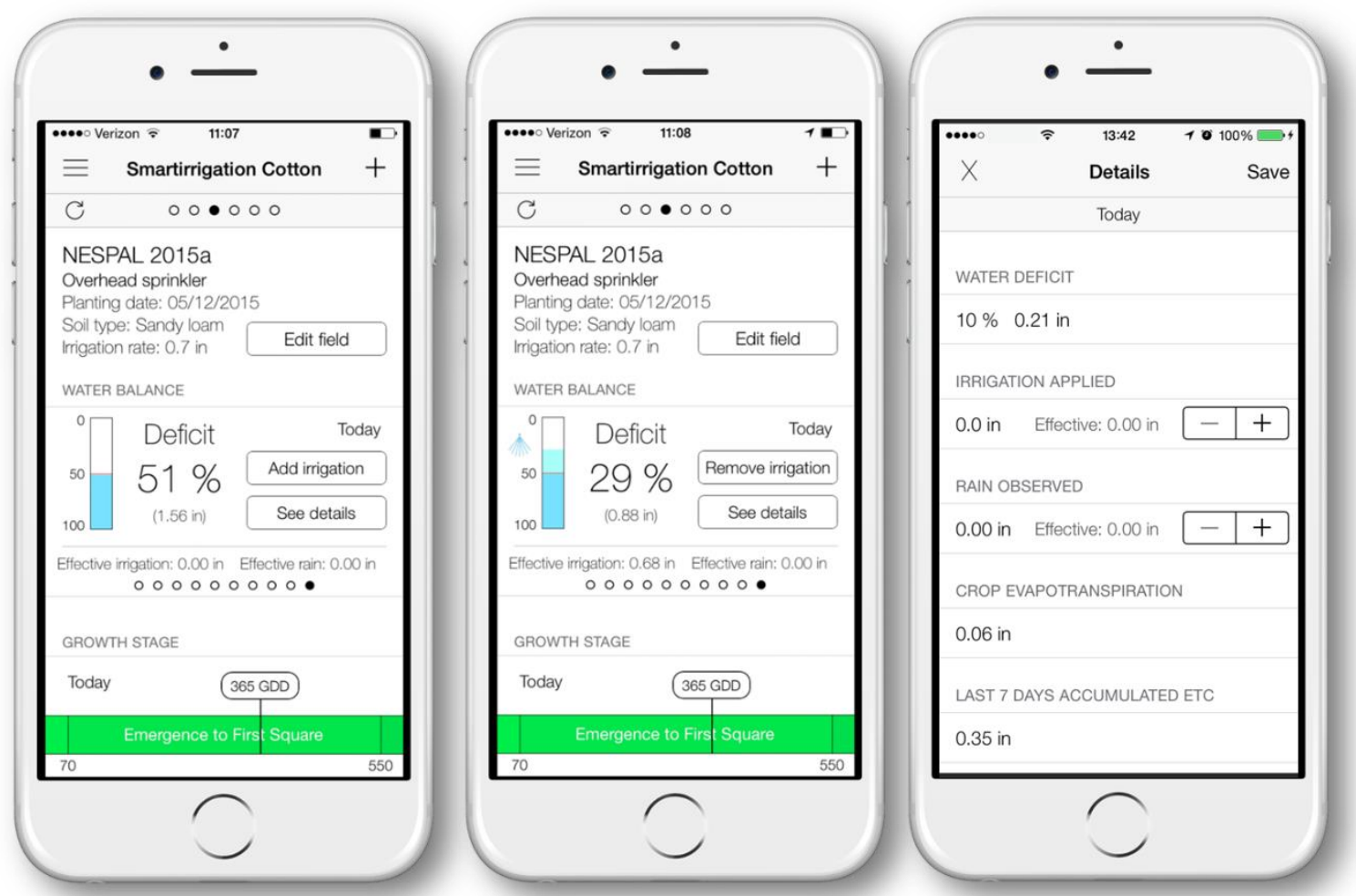

Fig. 5. Screenshots showing the main user-interface screen of the Cotton App (left and center). On each of these screenshots, the user can view information about the RZSWD, whether precipitation was recorded or irrigation was applied within the past day, as well as the phenological stage of the crop. Any of this information can be edited by tapping on the "See details" button. If irrigation events were not recorded properly, they can be added or removed. The screenshot on the right shows the details page where irrigation and rain amounts can be edited.

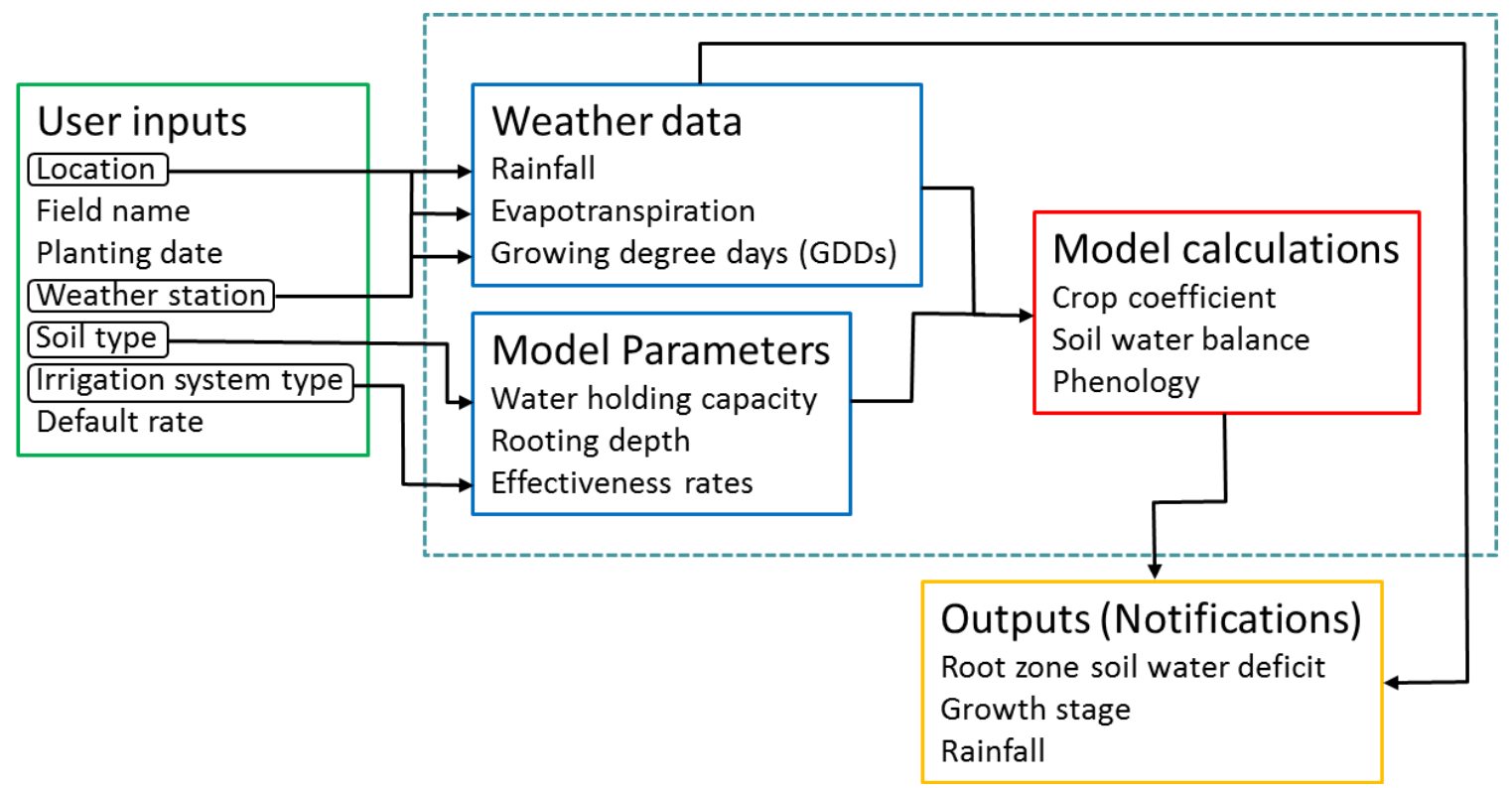

Fig. 6. Flow of information in the Cotton App. Components internal to the model are enclosed by the dashed line. 


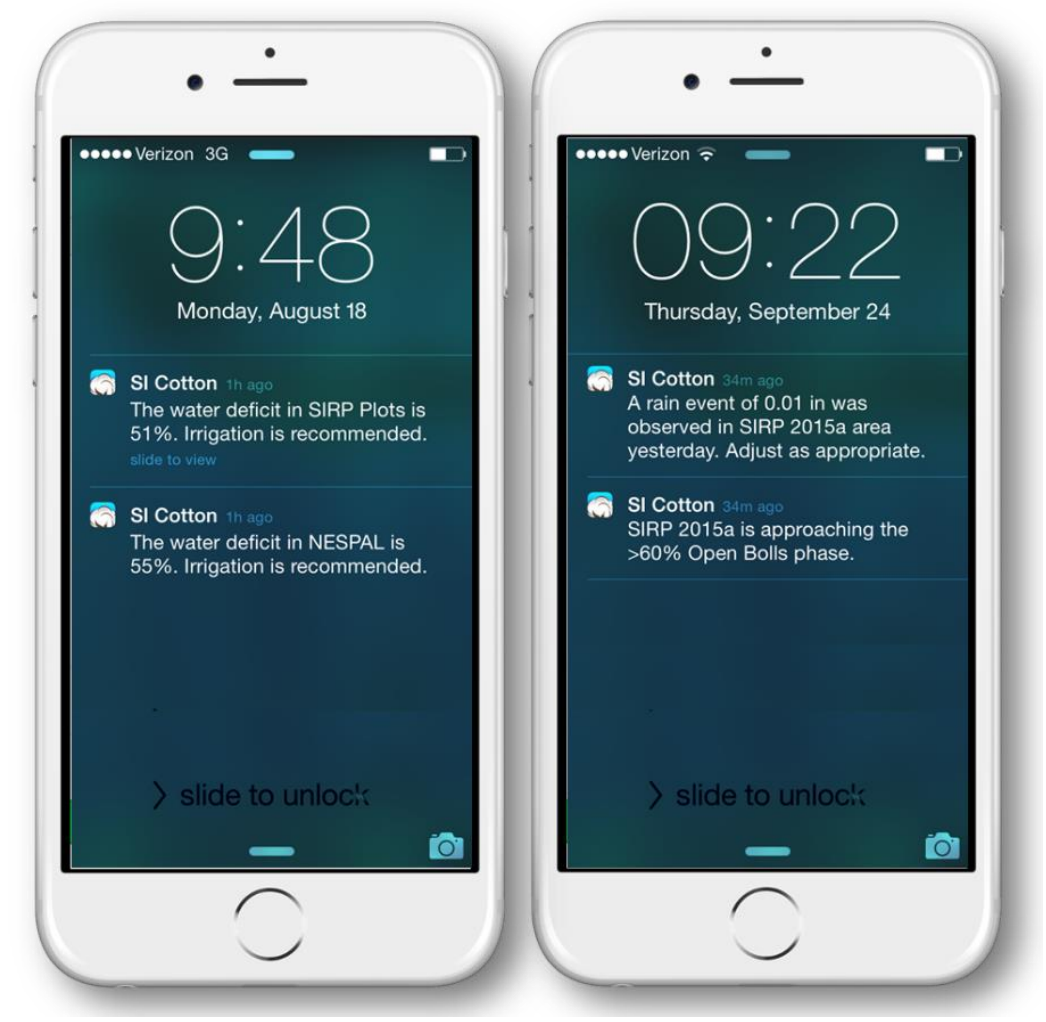

Fig. 7. Screenshots showing notifications for RZSWD (left), rain (right) and phenology change (right). 

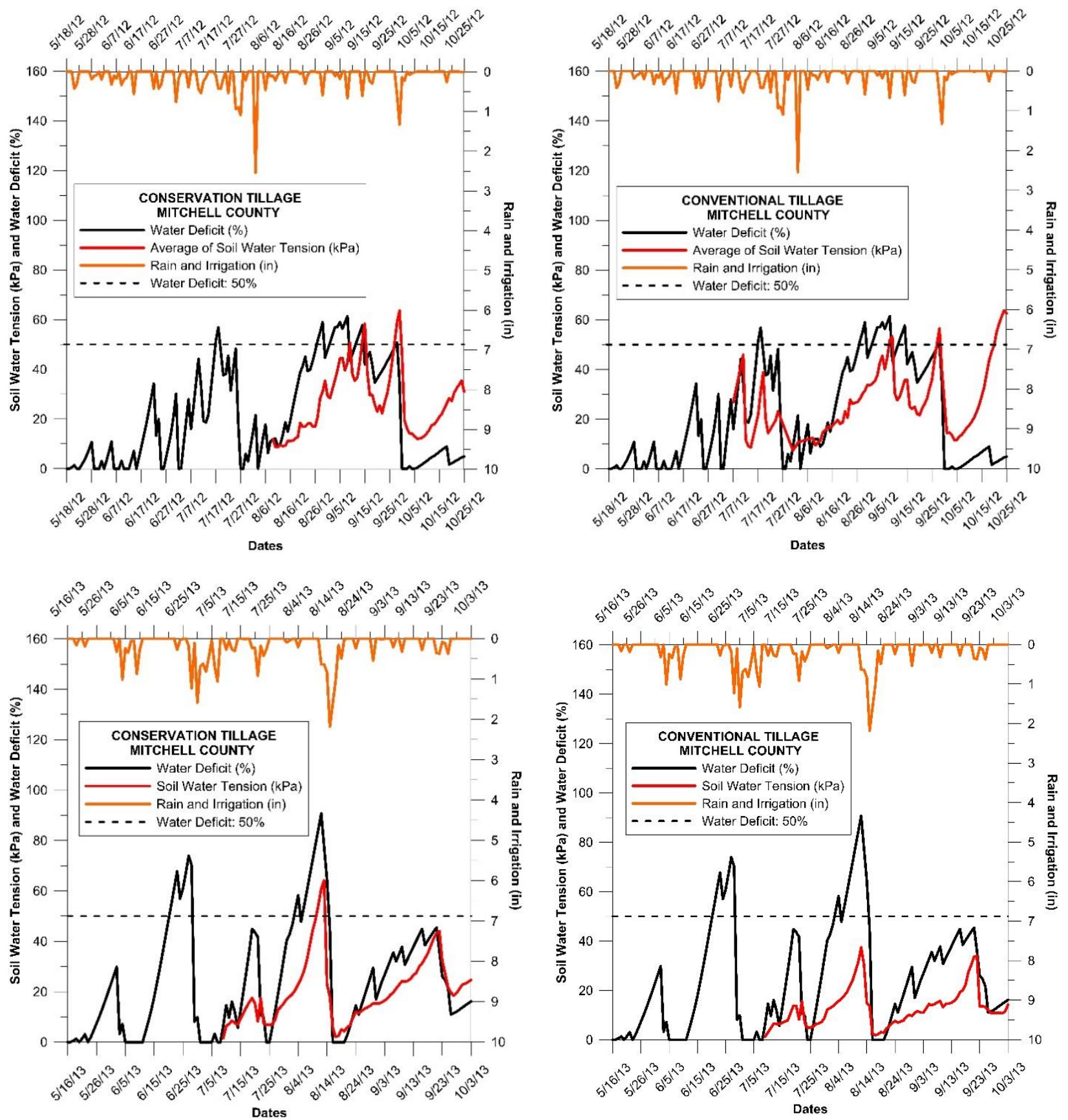

Fig. 8. Comparison of weighted soil water tension and RZSWD (\%) in conservation and conventional tillage plots at SIRP in 2012 (top) and 2013 (bottom). The soil water tension curves are the weighted average of measured soil water tension at $0.2,0.4$, and $0.6 \mathrm{~m}$. The 2013 curves reflect the fully calibrated Kc curves. 

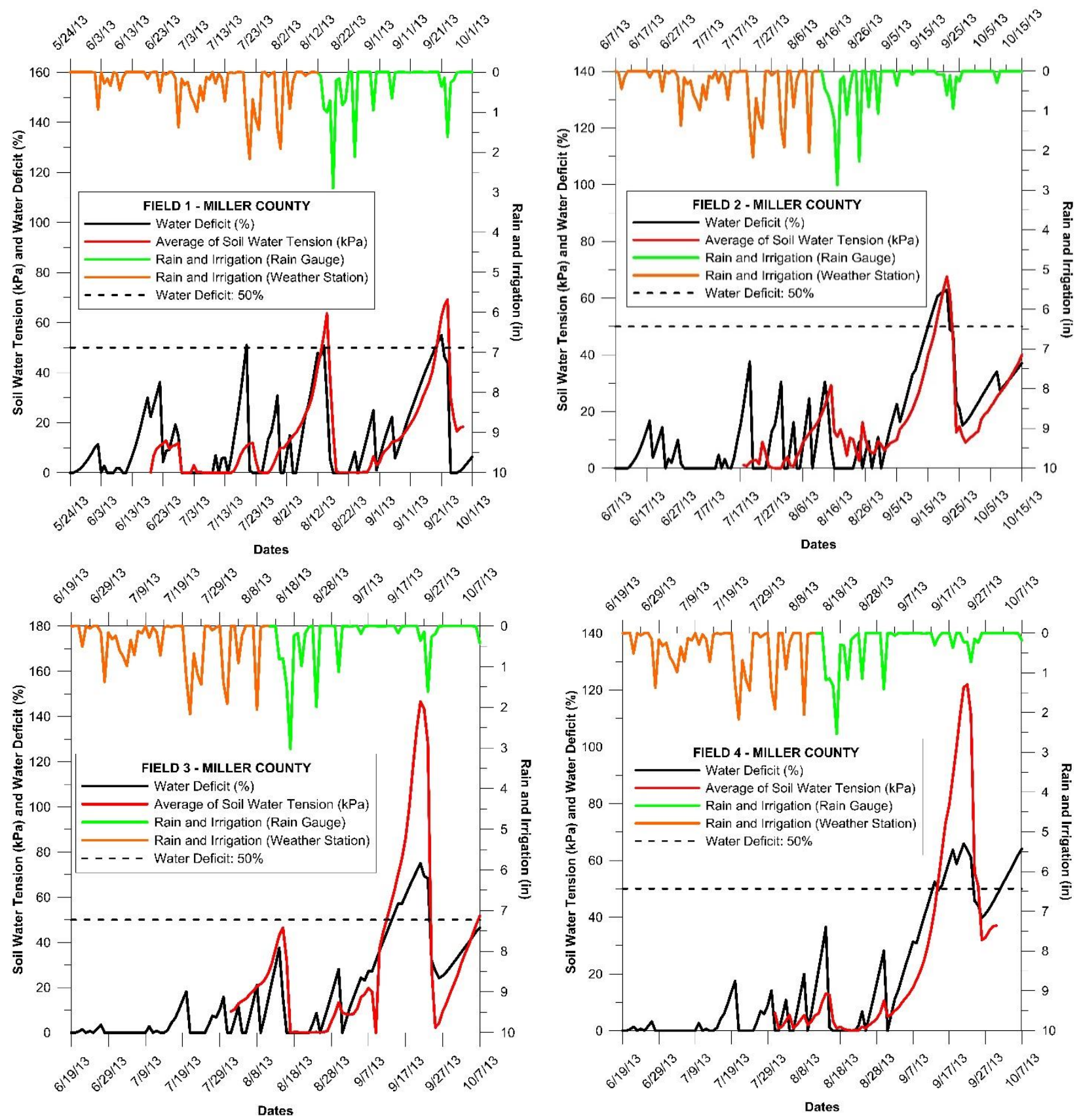

Fig. 9. Comparison of weighted soil water tension and RZSWD (\%) in four commercial cotton fields during 2013. The RZSWD curves were developed using the fully calibrated Kc curve. The soil water tension curves are the weighted average of measured soil water tension at $0.2,0.4$, and $0.6 \mathrm{~m}$. 


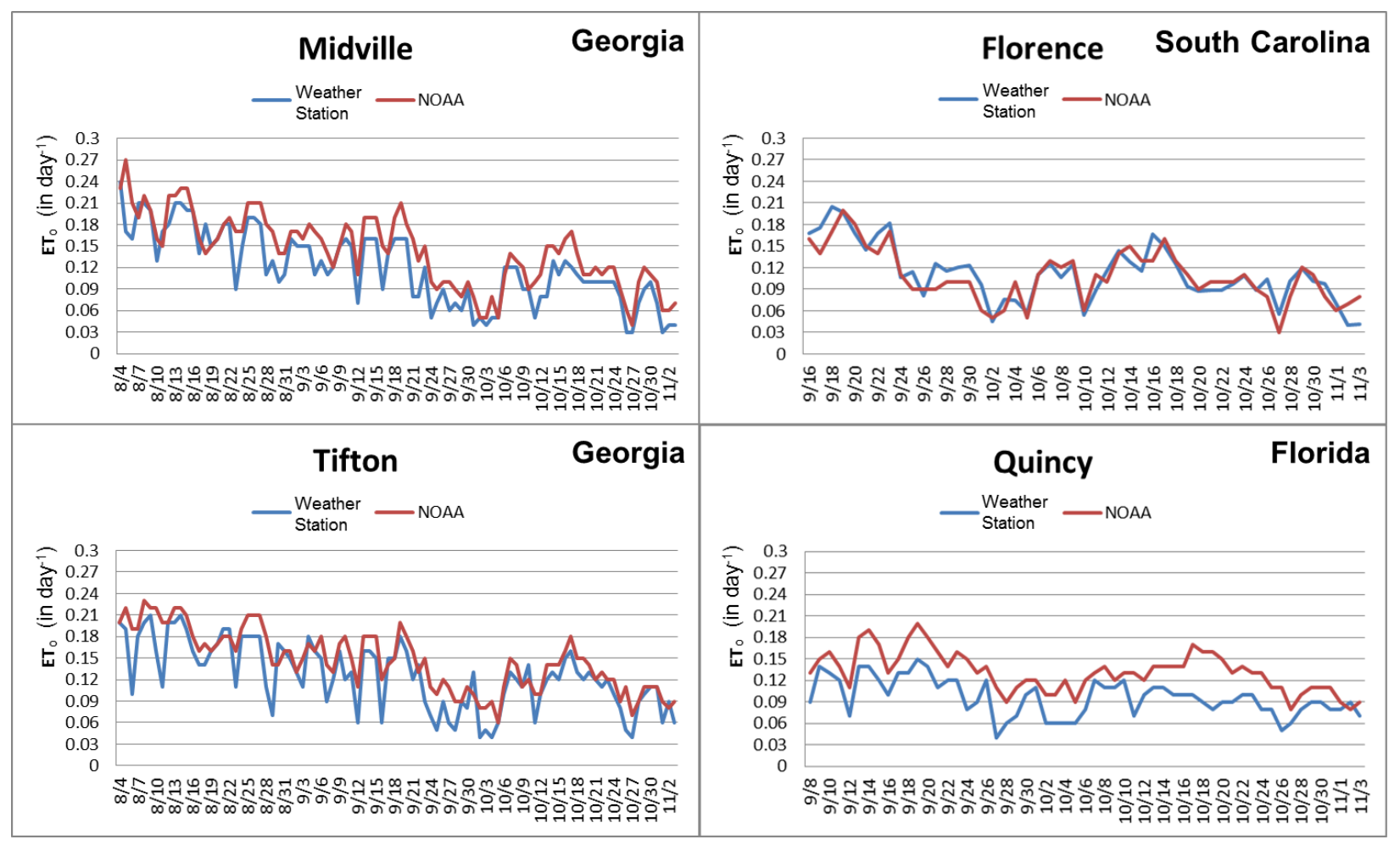

Fig. 10. Comparison of FAO 56 evapotranspiration (ETo) from the NOAA FRET tool and calculated from weather station meteorological data. 

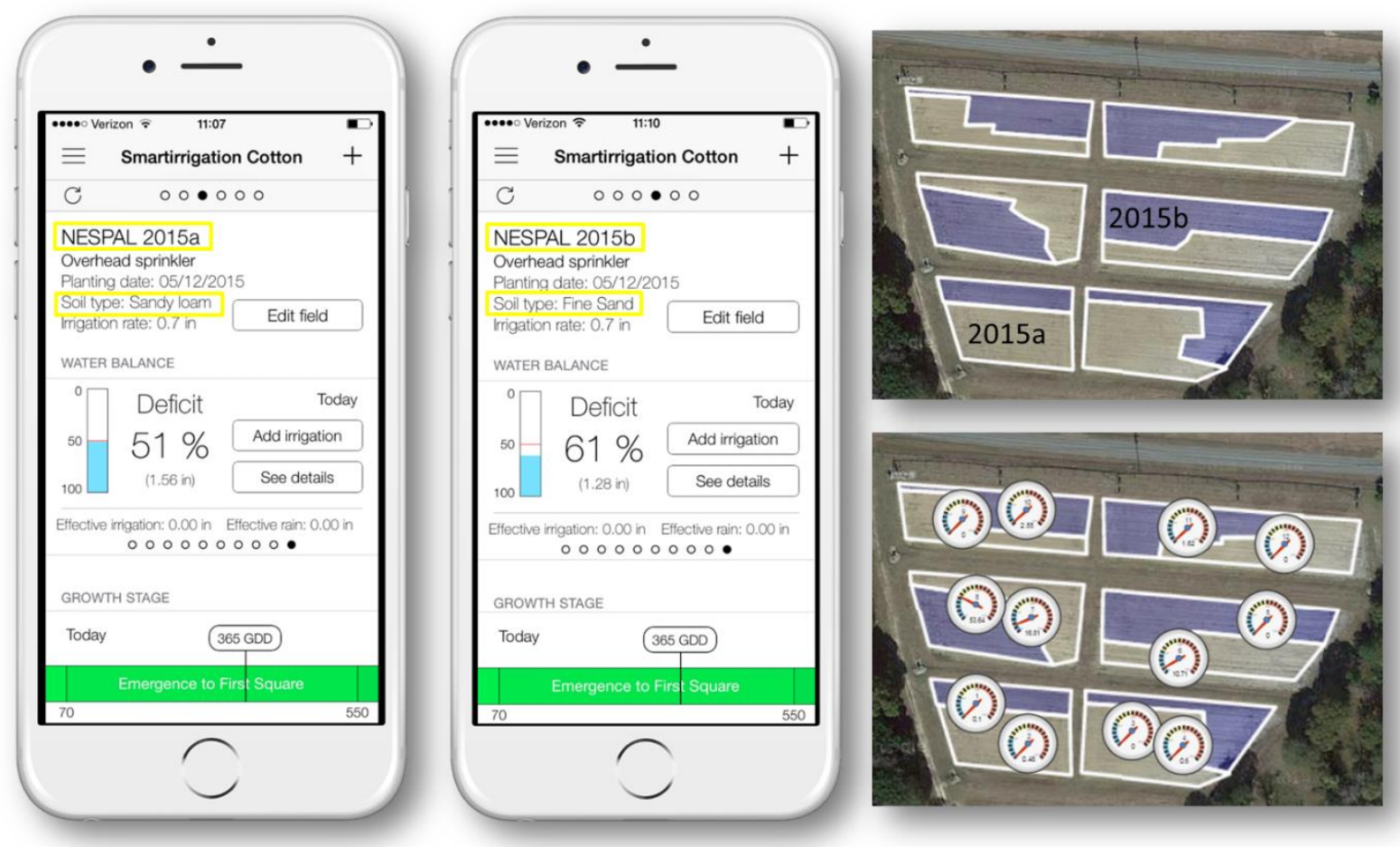

Fig. 11. The research field at the right was delineated into two IMZs (2015a and 2015b) using soil electrical conductivity as a surrogate for soil texture. The two IMZs were registered as individual fields and the RZSWDs for each IMZ were used to create VRI prescription maps when irrigation was needed. Each IMZ received a different irrigation amount from the field's VRI-enabled pivot. The gages in the field indicate location of UGA SSA sensor node locations. The two different RZSWDs are the result of differences in soil texture between the IMZs. 